\title{
Prevalence, patterns and predictors of self-medication with anti-malarial drugs among Cameroonian mothers during a recent illness episode
}

\author{
L. P. F. Kojom ${ }^{1}$, A. A. Ntoumba ${ }^{1}$, H. Nyabeyeu Nyabeyeu ${ }^{1}$, G. Bunda Wepnje², C. \\ Tonga ${ }^{1}$ and L. G. Lehman ${ }^{1,3}$ \\ ${ }^{1}$ Faculty of Sciences, ${ }^{3}$ Faculty of Medicine and Pharmaceutical sciences, University of Douala, Douala, ${ }^{2}$ Department of Zoology and \\ Animal Physiology, Faculty of Science, University of Buea, Buea, Cameroon
}

\begin{abstract}
Artemisinin-based combination therapies (ACTs) are recommended as treatment of choice for malaria. Although the resistance to artemisinin and its derivatives has not yet been officially reported in Africa, there is growing concern that it may reach the continent. Self-medication is common among African populations and may explained drug resistance. Unfortunately, a few studies have addressed this issue in Cameroon. This study seeks to appraise the prevalence, patterns and predictors of antimalarial self-medication. A household-based cross-sectional study was conducted in 2016 in the town of Douala. Interviews and pretested semi-structured questionnaires were administered for collecting information from 213 mothers of under-fives. The prevalence of self-medication was $49.30 \%$. The main reasons were "habit" (38.75\%), "Lack of money" (22.48\%) and "Lightness of symptoms" (13.18\%). Pharmacy (47.80\%) and street medicine stores $(30.19 \%)$ were the commonest drug providers. Nearly $20 \%$ of women had not respected posology although treatment was right and taken promptly. Age, level of education and curiosity on treatment were risk factors of self-medication. Our study confirms that malaria self-medication is common among women and the influence of some factors. Hence, strategies for information, education and communication should be scaled up to efficiently address self-medication in the area.
\end{abstract}

Journal of Medical and Biomedical Sciences (2018) 7(1), 29 - 39

Keywords: Self-medication, mothers of under-fives, prevalence, patterns, predicators, Douala.

\section{INTRODUCTION}

Since the implementation of artemisinin-based combination therapies (ACTs) as first-line treatment associated with preventive and vector control measures in control policies, malaria has greatly decreased in most endemic countries. Indeed, between 2000 and 2015 the number of cases and deaths attributable to malaria has decreased by nearly $41 \%$ and $62 \%$ respectively all over the world (WHO, 2016).

Furthermore, mortality rates were reduced by $40 \%$ or more between 2010 and 2015 in 39 out of 91 countries and areas where malaria transmission was

Correspondence: Prof. Lehman Leopold Gustave, Faculty of Sciences, Faculty of Medicine and Pharmacentical sciences, University of Douala, Douala, Cameroon.

E-mail: leopoldlehman@gmail.com active (WHO, 2016). However, malaria still remains an important public health concern in endemic areas especially in sub-Saharan Africa (SSA). According to the World Health Organization (WHO), an estimated 216 million of malaria cases and 445000 deaths occurred worldwide in 2016. The large majority of these were reported in the WHO African region which concentrated about $90 \%$ and $91 \%$ of all malaria cases and deaths respectively. Children under five years and pregnant women remain the major groups at risk for malaria (WHO, 2017).

Drug resistance may explain the difficulties encountered in malaria control interventions. It was primarily defined as the "the ability of a parasite strain to survive and/or multiply despite the administration and absorption of a drug in doses equal to or higher than those usually recommended but within the limits of tolerance of the subject" (Bruce- 


\section{Self-medication among Cameroonian mothers}

Kojom et al.,

Chwatt et al., 1986). This official WHO definition, based on clinical and parasitological criteria, was established when pharmacology, genetics and parasites culture techniques were not as sophisticated as those used nowadays (Basco and Ringwald, 2000). This definition was later edited to specify that this drug must "gain access to the parasite or the infected red blood cell for the duration of the time necessary for its normal action" (Bruce-Chwatt et al., 1986; WHO, 2001).

Resistance to antimalarial drugs has been described for Plasmodium falciparum and Plasmodium vivax, the main two species responsible for malaria burden. P. falciparum is the deadliest species and has developed resistance to nearly all antimalarial in current use especially ACTs. The emergence and spread of malaria parasites resistant to ACTs is now reported and well-established in Southern Asia areas (Wongsrichanalai and Sibley, 2013; Paloque et al., 2016; WHO, 2016; Dama et al., 2017) and is no doubt one of the most leading challenges which is facing endemic Asian countries (White, 2004; White et al., 2015).

Drug resistance has been implicated in the spread of malaria to new areas and re-emergence of malaria in areas where the disease had been eradicated (WHO, 2001). Drug resistance has also played a significant role in the occurrence and severity of epidemics in some parts of the world. Population movement has introduced resistant parasites to areas previously free of drug resistance (WHO, 2001; White, 2004). Thus, monitoring parasite resistance to artemisinins or to ACT partner drugs is critical for malaria control. Although the resistance to artemisinin and its derivatives has not yet been officially reported in Africa, there is growing concern that it may reach the continent.

Self-medication is mainly involved in the emergence of antimalarial drug-resistance (White, 2004; White et al., 2015). It can be defined as the use of drugs to treat self-recognized disorders or symptoms or the intermittent or continued use of a prescribed drug for chronic or recurrent diseases or symptoms without the advice of a physician (WHO, 2000). The practice is very common especially in developing countries where a large proportion of individuals has detectable concentrations of chloroquine in the blood for instance (White, 2004). Drugs that are prone to self-medication include analgesics, antimalarials, antibiotics and cough syrups, among others (Afolabi, 2008). The abuse of drugs raises the level of selection pressure exerted to parasites and consequently the chances of appearance of drug-resistant parasites (Shah et al., 2015). Thus, it is of utmost importance to appraise the level of self-medication with antimalarial drugs and depict its patterns and associated factors in a given area in order to adequately define and implement any control interventions.

Some researchers addressed these issues in Africa (Akanbi et al., 2005; Afolabi, 2008; Omole and Onademuren, 2010; Jombo et al., 2011; Chipwaza et al., 2014; Ocan et al., 2014) and their main findings reported a high prevalence of self-medication. In Cameroon, a few studies outlined this practice is present (Ndo et al., 2011; Makoge et al., 2013; Moyou-Somo et al., 2013; Nsagha D. S., 2013) but however data in Douala, the main business town of the country, are deeply missing. In addition, to the best of our knowledge, there is no study of interest that has addressed drug abuse practice among mothers who are the main household caregivers in Cameroon. Hence, this study was conducted to determine the prevalence, patterns and factors associated with self-medication with antimalarial drugs among mothers living in Douala.

\section{MATERIALS AND METHODS}

\section{Study site}

This pilot study was conducted in Douala $\left(04^{\circ} 03^{\prime} \mathrm{N}\right.$ $\left.09^{\circ} 41^{\prime} \mathrm{E}\right)$, the main economical city of Cameroon. The city and its surrounding consist of about more than 3000000 inhabitants. The city lies on the River Wouri estuary in a degraded Atlantic rainforest. The climate is typically warm and humid with an average annual temperature and an average humidity of $27.0 \quad{ }^{\circ} \mathrm{C}$ and $85 \%$ respectively (WEATHERBASE, 2017). It has a tropical climate with two main seasons, a dry season from November to February and a rainy season from March to October. However, the city sees rainfall throughout 
the year with an average rainfall of $3,600 \mathrm{~mm}$ per year (World Meteorological Organization, 2017). These environmental conditions are favourable for proliferation of breeding sites for vectors of malaria. The absence of data on malaria-related selfmedication practices guided the choice of Makepe district as study site.

Makepe is a district located in the Douala Five (Douala V) Subdivision, Wouri Division in the Littoral Region. It has a heterogeneous population comprising of various ethnic groups mainly represented by the Bamileke, Duala and Bassa. The population practices several occupational activities within the formal sector due to the presence of hundreds of enterprises as well as within the informal sector (www.doualazoom.com). Makepe district lies on a swampy area where there is collection of stagnant waters and scattered brushwood are frequently encountered. A few residence houses are built with materials such as plank or sheet-material.

\section{Study population}

The study population consisted of 213 women recruited in a consecutive manner as presented in Figure 2. Any mother with child aged less than five years old, $\geq 21$ years and having reported an episode of uncomplicated illness within the last six months and willing to participate was included in the study. Conversely, any woman who did not meet up with at least one of the abovementioned criteria was excluded from the study.

\section{Study design}

This cross-sectional survey was conducted from September to November 2016 in the Makepe district (Douala, Littoral region, Cameroon). Random sampling method was used for selection of homes. We included in this study, households where mothers of children under five years were present. The objectives and benefits of the study were explained to mothers in their homes. After obtaining written consent form, a questionnaire through standardized individual interview was administered to collect data of interest. Mothers were educated on the dangers of malaria and self-medication after the interview.

\section{Self-medication among Cameroonian mothers Kojom et al.,}

\section{Questionnaire}

Data on each participant was collected through an interview and an administration of a semistructured pre-tested questionnaire. The interview of each woman lasted for 20-25 minutes. The first part of the questionnaire was to collect sociodemographic characteristics which included age, level of education, marital status, occupation, region of origin, religion and age of the youngest child. The second part was designed to collect information on self-medication with antimalarial drugs. The respondents were asked which drugs they took, their source, how the use of drug was initiated (i.e., therapeutic itinerary) how they were taking these drugs (dose, i.e. capsules/tablets), how long they spent taking the drugs, how much time has elapsed between the onset of symptoms and treatment seeking behavior. We analyzed this information to know whether the treatment was right, prompt and the compliance had been respected. Additionally, each woman was asked why she self-medicated and symptoms they presented during their illness episode.

\section{Operational definitions}

Self-medication $=$ the use of drugs to treat selfrecognized disorders or symptoms without the advice of a physician (WHO, 2000).

Self-medication with antimalarial drugs $=$ the use of antimalarial drugs to treat selfrecognized disorders or symptoms without the advice of a physician.

Right antimalarial treatment $=$ Antimalarial treatment used by individuals and that is in line with national treatment guidelines on management of uncomplicated malaria episodes.

Prompt antimalarial treatment $=$ Antimalarial treatment taken between 12 and 24 hours after onset of symptoms (WHO, 2005). In this study, we used a less restrictive definition. Thus, we considered the treatment was prompt if the participant took it less than 24 hours after onset of symptoms.

Late antimalarial treatment $=$ Antimalarial treatment taken more than 24 hours after onset of symptoms (WHO, 2005). 


\section{Self-medication among Cameroonian mothers}

Kojom et al.,

Bad treatment compliance $=$ we used this term to define the non-respect of the treatment posology in terms of duration, frequency and dose of the treatment.

\section{Ethical approval}

The study was approved by the institutional review board (IRB) of the University of Douala under $\mathrm{N}^{\circ}$ CEI-UD/270/09/2015/T. Besides, administrative clearance was sought from Regional Delegation of Public Health for Littoral. In addition, written consent forms were obtained from each participant before their inclusion in the study. Objectives, gains and risks of the study were explained to each woman in the language they understood best. They were informed about the confidential and noncompulsory aspect of the study and were free to withdraw at any time.

\section{Statistical analysis}

All data were verified for consistency, coded, and keyed into an Excel spreadsheet and thereafter analyzed with the Statistical package for social science (SPSS) version 22 for Windows (SPSS Inc., Chicago, IL, USA). Data were presented as percentage (confidence interval at $95 \%$ ) or mean \pm standard deviation (SD) where appropriate. The confidence intervals at 95\% were computed as previously described elsewhere (Wilson, 1927; Newcombe, 1998). Independence chi-square $\left(\chi^{2}\right)$ and Fisher's exact tests were used to compare proportions. Univariate and multivariate logistic regression models were used to identify predictors of self-medication with antimalarial drugs. These allowed to quantify the association between self-medication and predictors in terms of odds ratio (OR). In this analysis, the prevalence of self-medication with antimalarial drugs was considered as the outcome or dependent variable. The sociodemographic and self-medication related variables were considered as the independent variables. Significance was set at $\mathrm{P}$-value $<0.05$.

\section{RESULTS \\ Sociodemographic characteristics of the study population}

In total, 213 participants aged $28.77 \pm 8.81$ years on average were included in the study. The median (interquartile range) was 26 years old (12.25). As presented in Table 1, women aged $15-25$ years old and $\geq 45$ years old accounted for $40.4 \%$ and $7.1 \%$ of the study population respectively. Most of the participants had attended university studies (56.1\%), 64.3\% were single, $50.5 \%$ were natives from the West region of Cameroon, $57.2 \%$ had informal employment and $57.2 \%$ were catholic faithfuls. Mothers aged 25-35 years accounted for $44.54 \%$ of all women having attended university studies (P-value < 0.0001). Besides, the youngest

\section{Table 1: Characteristics of the participants}

\begin{tabular}{lc}
\hline Variables & Frequency (\%) \\
\hline Age (years) & \\
$15-25$ & $86(40.4 \%)$ \\
$25-35$ & $74(34.7 \%)$ \\
$35-45$ & $38(17.8 \%)$ \\
$\geq 45$ & $15(7.1 \%)$ \\
Level of education & \\
Uneducated & $5(2.4 \%)$ \\
Primary & $20(9.4 \%)$ \\
Secondary & $68(32.1 \%)$ \\
University & $119(56.1 \%)$ \\
Occupation & \\
Informal employment & $116(57.2 \%)$ \\
Formal employment & $21(10.5 \%)$ \\
Unemployed & $66(32.3 \%)$ \\
Marital status & \\
Single & $137(64.3 \%)$ \\
Married & $66(31.9 \%)$ \\
Widow & $8(3.8 \%)$ \\
Region of origin & \\
West & $104(50.5 \%)$ \\
Littoral & $55(26.7 \%)$ \\
Centre & $22(10.7 \%)$ \\
Others & $25(12.1 \%)$ \\
Religion & \\
Catholic & \\
Protestant & $111(57.2 \%)$ \\
Muslim & $44(22.7 \%)$ \\
Other & $13(6.7 \%)$ \\
Age of the youngest child (months) & \\
$0-12$ & $75(35.1 \%)$ \\
12 - 24 & $14(6.4 \%)$ \\
$24-36$ & $36(16.9 \%)$ \\
$36-48$ & $44(20.8 \%)$ \\
$48-60$ & $44(20.8 \%)$ \\
\hline Data presented a for & \\
\hline &
\end{tabular}

Data presented as frequency (percentage) 
child was aged between 0 and 12 months and they accounted for $35.1 \%$ (Table 1 ).

\section{Prevalence of self-medication}

Out of 213 women enrolled in the study, 155 reported having self-medicated with drugs during their last febrile episode. Thus, the prevalence of selfmedication was $72.77 \%$ (155/213; 95\%CI: 66.4378.31).

\section{Prevalence of self-medication with anti-malarial drugs}

Out of the 155 respondents who self-medicated, we reported that 105 of them effectively consumed antimalarial drugs after analysis of answers. The prevalence of self-medication with antimalarial drugs was 49.30\% (105/213; 95\%CI: 42.66-55.97). We noted that analgesics (26 women, 52.0\%) and traditional medicines (24 women, $48.0 \%$ ) were used in the remaining 50 women who reported having selfmedicated.

In addition, analgesics and antipyretics drugs reported by respondents consisted of Paracetamol, Doliprane, Efferalgan, Dafalgan and Ubumol while those on traditional medicines consisted of decoc-

Table 2: Antimalarial-drugs used for self-medication

\begin{tabular}{lc}
\hline Antimalarial Drug & Frequency (\%) \\
\hline ACTs* (89.53\%) & $62(59.06 \%)$ \\
Coartem & $6(5.71 \%)$ \\
Bimalaril & $6(5.71 \%)$ \\
Malacur & $4(3.81 \%)$ \\
Arthemether & $3(2.86 \%)$ \\
Artequin & $3(2.86 \%)$ \\
Artesunate & $3(2.86 \%)$ \\
Duocotexine & $2(1.9 \%)$ \\
Artefan & $1(0.95 \%)$ \\
Amodiaquine & $1(0.95 \%)$ \\
Combiart & $1(0.95 \%)$ \\
Laritem & $1(0.95 \%)$ \\
Lumantem & $1(0.95 \%)$ \\
Synrian & \\
Sulfonamides/Antiparasitic (5.71\%) & $6(5.71 \%)$ \\
Maloxine & \\
4-aminoquinolines (4.76\%) & $5(4.76 \%)$ \\
Quinine/Nivaquine &
\end{tabular}

*ACTs $=$ Artemisinin-based combination therapies
Self-medication among Cameroonian mothers Kojom et al.,

tions, maceration and infusion of medicinal plants associated with milk or honey.

Symptoms treated by women who selfmedicated with antimalarial drugs

Fever (47.58\%), headache $(19.35 \%)$ and fatigue $(11.29 \%)$ were the most reported symptoms by the respondents who practiced self-medication. Fifteen

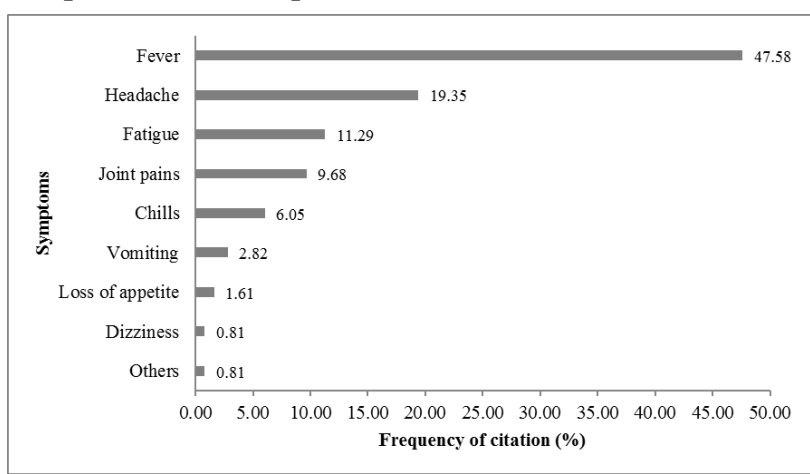

Figure 1: Symptoms presented among women who self-medicated with antimalarial drugs

(15) women presented three symptoms during their last febrile episode (Figure 1).

\section{Treatment practices in management of recent} febrile episodes

Three classes of antimalarial drugs mainly represented by Artemisin-based combination therapies $(89.53 \%)$ were reported by the mothers. The remaining classes included sulfonamides/antiparasitic and 4-aminoquinolines (Table 2). The ArtemetherLumefantrine combination $(59.06 \%$ ) was the most used antimalarial drug in self-medication. This was referred to as Coartem by most of the respondents.

\section{Sources of drugs and therapeutic itinerary}

We found that the providers of antimalarial drugs used in self-medication were pharmacy $(47.80 \%)$, street sellers $(30.19 \%)$, public health facilities $(17.61 \%)$ and friend/neighbour/family member $(4.40 \%)$.

The patterns of health seeking behavior among women who self-medicated are presented in Table 3. The majority of them primarily managed their febrile episode at home $(78.10 \%)$ before going to street sellers $(45.71 \%)$ or public facility/pharmacy $(32.39 \%)$. One woman obtained antimalarial drugs 


\section{Self-medication among Cameroonian mothers}

Kojom et al.,

Table 3: Therapeutic itinerary of the women who self-medicated with antimalarial drugs

\begin{tabular}{lc}
\hline Therapeutic itinerary & Frequency (\%) \\
\hline Home-Street sellers & $48(45.71 \%)$ \\
Home-Hospital/Pharmacy & $34(32.39 \%)$ \\
Pharmacy & $22(20.95 \%)$ \\
Street sellers-Pharmacy & $1(0.95 \%)$ \\
\hline
\end{tabular}

Data presented as frequency (percentage)

from street sellers before going to pharmacy.

Reasons for self-medication with antimalarial drugs

Many reasons were reported to explain the selfmedication with antimalarial drugs. The leading reasons included "habit", "lack of money" and "lightness of symptoms" that accounted for $38.78 \%$, $22.48 \%$ and $13.18 \%$ of all reasons respectively (Table 4). Importantly, the majority $(57.14 \%)$ of women who gave "Habit" as reason for selfmedication were aged between 25 and 35 years (P-value 0.0401).

Table 4: Reasons for self-medication with antimalarial drugs

\begin{tabular}{lc}
\hline Reasons for self-medication & Citation (\%) \\
\hline Habit & $50(38.75 \%)$ \\
Lack of money & $29(22.48 \%)$ \\
Lightness of symptoms & $17(13.18 \%)$ \\
Long waiting time at hospital & $9(6.98 \%)$ \\
Advise of a friend/family member & $8(6.2 \%)$ \\
Know it is an antimalarial drug & $4(3.1 \%)$ \\
Prevention & $2(1.55 \%)$ \\
Urgent situation & $2(1.55 \%)$ \\
Easy to obtain & $2(1.55 \%)$ \\
No severe adverse effects & $1(0.78 \%)$ \\
Others & $5(3.88 \%)$ \\
\hline
\end{tabular}

Data presented as frequency (percentage)

Characteristics of the antimalarial treatment

It was noted that more than one third (37.26\%) of the women taken promptly their antimalarial treatment less than 24 hours before the onset of first symptoms while $45.75 \%$ and $16.99 \%$ took it between 24 and 48 hours and more than 48 hours respectively. A further depth analysis revealed that most of the participants $(67.27 \%)$ had adequately self-managed their last febrile episode. Indeed, the antimalarial therapy was taken promptly and the posology was respected. Conversely, 23.64\% (20\% $+3.64 \%$ ) did not respect the posology of treatment although it was right (Table 5). This was mainly related to the shortening of the duration of the therapy course. Indeed, women reported having used Coartem less than three days during their last illness episode for instance.

Table 5: Characteristics of antimalarial treatment in women who self-medicated

\begin{tabular}{ll}
\hline Characteristics of treatment & Frequency (\%) \\
\hline Right, prompt and good compliance & $37(67.27 \%)$ \\
Right, prompt but bad compliance & $11(20.0 \%)$ \\
Right, late but good compliance & $4(7.27 \%)$ \\
Right but late and bad compliance & $2(3.64 \%)$ \\
Wrong but taken promptly & $1(1.82 \%)$ \\
\hline
\end{tabular}

Data presented as frequency (percentage)

Factors associated with self-medication with anti-malarials

The quantification of risk for self-medication with antimalarial drugs is summarized in Table 6. Three factors namely age, level of education and need more information on antimalarial treatment were associated with an increased risk of self-medication. Indeed, women aged 25-35 years were nearly four folds $(\mathrm{OR}=3.44 ; 95 \% \mathrm{CI}: 1.25-9.45 ; \mathrm{P}$-value $=$ $0.0165)$ more at risk to practice self-medication than those aged between 15 and 25 years (Table 6). In addition, women having attended university level and outlining the need for more information on treatment had nearly 12 folds $(\mathrm{OR}=11.65 ; 95 \% \mathrm{CI}$ : $1.02-133.15 ; \mathrm{P}$-value $=0.0483)$ and six folds $(\mathrm{OR}$ $=5.96 ; 95 \% \mathrm{CI}: 1.32-26.93$; P-value $=0.0204)$ more of risk to self-medication than illiterate and those having no idea on the question respectively.

\section{DISCUSSION}

Self-medication is a real problem of public health as it is involved in the emergence and spread of drugresistance all over the world especially in Africa where malaria is highly prevalent. This study aimed at appraising the prevalence, describing the patterns and identifying predictors of self-medication with antimalarial drugs among Cameroonian mothers 


\section{Self-medication among Cameroonian mothers}

Kojom et al.,

Table 6: Factors associated with self-medication with anti-malarials

\begin{tabular}{|c|c|c|c|c|}
\hline Factors & Raw OR $(95 \% \mathrm{CI})$ & P-value & Adjusted OR $(95 \% \mathrm{CI})$ & P-value \\
\hline \multicolumn{5}{|l|}{ Age (yrs) } \\
\hline $15-25$ & 1 & & 1 & \\
\hline $25-35$ & $3.53(1.57-7.91)$ & 0.0022 & $3.44(1.25-9.45)$ & 0.0165 \\
\hline $35-45$ & $1.09(0.48-2.45)$ & 0.8422 & $1.36(0.42-4.41)$ & 0.6099 \\
\hline $45-55$ & $3.82(0.81-18.12)$ & 0.0911 & $4.00(0.58-27.76)$ & 0.1607 \\
\hline \multicolumn{5}{|l|}{ Marital status } \\
\hline Single & 1 & & 1 & \\
\hline Married & $0.89(0.46-1.73)$ & 0.7343 & $0.73(0.27-1.97)$ & 0.5388 \\
\hline Widow & $2.58(0.31-21.72)$ & 0.3835 & $4.09(0.26-63.38)$ & 0.3133 \\
\hline \multicolumn{5}{|c|}{ Level of education } \\
\hline Illiterate & 1 & & 1 & \\
\hline Primary & $1.44(0.19-11.04)$ & 0.7231 & $7.98(0.56-112.99)$ & 0.1245 \\
\hline Secondary & $1.11(0.17-7.13)$ & 0.9116 & $3.64(0.34-38.57)$ & 0.2841 \\
\hline University & $2.79(0.44-17.71)$ & 0.277 & $11.65(1.02-133.15)$ & 0.0483 \\
\hline \multicolumn{5}{|l|}{ Occupation } \\
\hline Formal & 1 & & 1 & \\
\hline Informal & $0.79(0.33-1.89)$ & 0.5935 & $0.55(0.18-1.62)$ & 0.2748 \\
\hline No employment & $0.81(0.34-1.92)$ & 0.6301 & $0.62(0.21-1.89)$ & 0.4041 \\
\hline \multicolumn{5}{|c|}{ Are antimalarial drugs dangerous? } \\
\hline Yes & 1 & & 1 & \\
\hline No & $1.46(0.72-2.94)$ & 0.2928 & $2.04(0.86-4.87)$ & 0.1076 \\
\hline \multicolumn{5}{|c|}{ Is information on treatment necessary? } \\
\hline No & 1 & & 1 & \\
\hline No idea & $2.80(0.46-16.93)$ & 0.2621 & $4.51(0.46-43.90)$ & 0.1941 \\
\hline Yes & $4.33(1.31-14.33)$ & 0.0164 & $5.96(1.32-26.93)$ & 0.0204 \\
\hline \multicolumn{5}{|c|}{ Correct knowledge on national first-line antimalarial treatment } \\
\hline No & 1 & & 1 & \\
\hline Yes & $2.10(0.41-10.75)$ & 0.3732 & $2.12(0.38-10.78)$ & 0.3031 \\
\hline
\end{tabular}

OR = Odds ratio; 95\%CI = Confidence interval at 95\%. Logistic regression models were used to quantify the association. $P$-values underlined were significant $(P$-value $<0.05)$

living in the town of Douala.

In this study, nearly half of the participants practiced self-medication with antimalarials during their last febrile illness. This is consistent with previous studies (Akanbi et al., 2005; Afolabi, 2008; Mazigo et al., 2010; Omole and Onademuren, 2010; Chipwaza et al., 2014; Ocan et al., 2015) that outlined this practice is common. This finding may be explained by the fact that malaria is particularly prevalent in Cameroon especially in Douala. The country accounted for about $16 \%$ of all malaria cases occurring in the central Africa region (WHO, 2016). This high level of malaria transmission associated with other factors such as socioeconomic status or level of education may explain this abusive drug use. Besides, the Artemether-Lumefantrine (AL) therapeutic association referred to as Coartem by the majority of the respondents was the main antimalarial drug used for self-medication. This was also reported by Ocan et al. (2014) in Uganda.

Many reasons for practicing self-medication were given by the respondents among which the main were "habit" (38.75\%), "lack of money" (22.48\%), "lightness of symptoms" $(13.18 \%)$ and "long waiting time at hospital" (6.98\%). These were also reported by Afolabi (2008) among female population from Ifako-Ijaive in Nigeria.

Pharmacies were the main antimalarial drug providers among women of this study. This figure is higher than those of Ndo et al. (2011) and Forero et al. (2014) who found $35.9 \%$ and $29.4 \%$ in Cameroon 


\section{Self-medication among Cameroonian mothers}

Kojom et al.,

and Colombia respectively. This finding highlights the easiness with which antimalarial drugs are obtained in pharmacies. This assertion is supported by our personal observations in our setting as well as those reported by the abovementioned authors. To be noted, a significant proportion $(30.19 \%)$ of respondents obtained treatment by street sellers/drug shops.

This value is lower than that of Makoge ${ }^{1}$ et al. (2013) and Moyou-Somo et al. (2013) but conversely higher than that Kinung'hi et al. (2010) and Ndo et al. (2011). These authors found $37.5 \%, 65 \%, 8.5 \%$ and $22.4 \%$ respectively. Drugs obtained from street sellers or drug shops are assumed to be of wellreduced quality owing to the absence of quality control and assurance measures (Ndo et al., 2011). This fact is confirmed by a previous study conducted in Douala that pointed out a higher rate of nonconformities in Arthemether-Lumefantrine 20/120 $\mathrm{mg}$ tablets obtained from the informal sector compared to legal sector (19.94\% versus 3.34\%). These included for instance the absence of active compounds and reduced friability and hardness (Nga et al., 2015).

This study pointed out a non negligible fraction of women who self-medicated did not respect the posology of antimalarial treatment. This was related to shortening of the duration of the therapy course. Indeed, women reported having used Coartem less than three days during their last illness episode for instance. (Afolabi, 2008) outlined the dangers of selfmedication in this sense it might result in abuses during treatment even though this is adapted to selfdiagnosed disease. The consequence of this finding is an under-dosing of treatment which may result in aggravation of symptoms and the emergence of drug -resistance (White, 2004; White et al., 2015).

Furthermore a recent study reported the emergence of an Artemisin-resistant strain of Plasmodium falciparum contracted by a Chinese tourist returnee from Equatorial Guinea in Africa (Lu et al., 2017). Although this putative case of Artemisin-resistance has to be supported by other studies, we reckon this first report should warn African governments and scien- tific community that the problem of the emergence and dissemination of malaria strains resistant to Artemisinins and its derivates is far from the utopia. In the case of such a scenario, the endeavours of governments will be strongly undermined. Thus, it is critical that governments of endemic countries especially Cameroon develop and implement policies aiming to inflect self-medication among populations. Policies integrating health campaigns based on communication for behaviour change would be greatly helpful for instance (Nsagha et al., 2011).

Nearly one in five women $(16.99 \%)$ sought their treatment more than 48 hours after onset of the symptoms of the febrile episode. This result agrees with the interval $(10 \%-28.9 \%)$ reported by Makoge ${ }^{1}$ et al. (2013) in the Southwest region of Cameroon. The World Health Organization (WHO) recommends seeking treatment within 12-24 hours after onset of any symptoms (WHO, 2005). Accordingly, this fraction of the study population would be more at risk of severe complications to health facilities.

Importantly, a few women self-medicated with analgesics for treating their self-diagnosed malaria episode. This result is in line with that of MoyouSomo and colleagues who reported such a misconception in four regions of Cameroon (MoyouSomo et al., 2013). Besides, traditional herbs were used by a few women outlining the importance of traditional beliefs for treating several disorders in Africa (Abdullahi, 2011; Nsagha et al., 2011). Selfmedication with traditional medicines has been reported to be the leading practice for first-line treatment of malaria (Idowu et al., 2008).

Three factors were associated with an increased risk of self-medication. Indeed, women aged 25-35 years were nearly four folds more at risk to practice self-medication than their counterparts aged $15-25$ years. This finding disagrees with previous reports that outlined either a higher self-medication rate in younger people (Paula Martins et al., 2002; Jain, 2011) or no influence of age (Afolabi, 2008). We think women aged 25-35 years would have had more history of malaria episodes than their younger counterparts and as a result they would have ac- 
quired more skills and self-confidence on treatment. In addition, higher the level of education of this age group could also explain this association between age and prevalence of self-medication. Our assumptions seem to be supported by two of our findings. Indeed, the majority $(57.14 \%)$ of women who gave "Habit" as reason for self-medication was aged between 25 and 35 years $(\mathrm{P}$-value $=0.0401)$. Also, this age group accounted for $44.54 \%$ of all women having attended university level (P-value $<0.0001)$. It would be interesting to carry out further sociological surveys in order to confirm our assumption in our setting.

The risk of self-medication with antimalarials was higher among women having attended university level. This is consistent with findings of Afolabi (2008), Jombo et al. (2011) and Sapkota et al. (2010) in Nigeria. This result may be explained by the fact that, these women can decrypt better drug-related instructions and be pruned to seek information on treatment of diseases through reading. This last explanation might explain why the risk of selfmedication was higher among women feeling the need for having more information about treatment. Indeed, the bulk of these women had mainly attended university level even though the association was not statistically significant.

\section{CONCLUSION}

This study outlined that self-medication with antimalarial drugs was common among mothers in the town of Douala. It also provides evidence that many abuses exist during management of febrile episode and the influence of factors such as age and level of education on the risk of self-medication with antimalarial drugs. Self-medication is a dangerous and hazardous practice on both individual and population scales as it is involved in late hospital consultation, complication of disease and the emergence of drugresistance. Thus, it would be critical to inform and educate population on the dangers of such a practice. Mothers should be primarily targeted by health campaigns as they are the main caregivers in households in Africa.
Self-medication among Cameroonian mothers Kojom et al.,

\section{COMPETING INTERESTS}

The authors declare that they have no competing interests.

\section{ACKNOWLEDGMENTS}

The authors are grateful to the administrative authorities of the town of Douala (Littoral region, Cameroon) who facilitated the implementation of this study. We are also grateful to mothers who gave their consent for the study as well as to Mr. KOUM Stephane (Department of Earth sciences, University of Douala, Cameroon) for providing maps of the study site.

\section{REFERENCES}

Abdullahi A.A. (2011) Trends and challenges of traditional medicine in Africa. African Journal of Traditional, Complementary and Alternative Medicines 8(5S).

Afolabi A. (2008) Factors influencing the pattern of self-medication in an adult Nigerian population. Annals of African medicine 7(3), 120127.

Akanbi O., Odaibo A., Afolabi K. and Ademowo O. (2005) Effect of self-medication with antimalarial drugs on malaria infection in pregnant women in South-Western Nigeria. Medical Principles and Practice 14(1), 6-9.

Basco L. and Ringwald P. (2000) Drug-resistant malaria: problems with its definition and technical approaches. Sante (Montrouge, France) 10(1), 47-50.

Bruce-Chwatt L.J., Black R.H., Canfield C.J., Clyde D.F., Peters W., Wernsdorfer W.H. and Organization W.H. (1986) Chemotherapy of malaria.

Chipwaza B., Mugasa J.P., Mayumana I., Amuri M., Makungu C. and Gwakisa P.S. (2014) Selfmedication with anti-malarials is a common practice in rural communities of $\mathrm{Ki}$ losa district in Tanzania despite the reported decline of malaria. Malaria journal 13(1), 252.

Dama S., Djimde A.A. and Doumbo O.K. (2017) Methods for monitoring artemisinin-based combination therapies efficacy. Clinical Reviews and Opinions 8(1), 1-13. 


\section{Self-medication among Cameroonian mothers}

Kojom et al.,

Forero D.A., Chaparro P.E., Vallejo A.F., Benavides Y., Gutiérrez J.B., Arévalo-Herrera M. and Herrera S. (2014) Knowledge, attitudes and practices of malaria in Colombia. Malaria journal 13(1), 165.

Idowu O., Mafiana C., Luwoye I. and Adehanloye O. (2008) Perceptions and home management practices of malaria in some rural communities in Abeokuta, Nigeria. Travel Medicine and Infectious Disease 6(4), 210-214.

Jain S. (2011) Concept of self medication: a review. International Journal of Pharmaceutical \& Biological Archive 2(3).

Jombo G., Mbaawuaga E., Alao O., Peters E., Dauda M., Okwori E., Akosu T., Etukumana E. and Yaakugh J. (2011) Choices of drugs for self-treatment of malaria among adult women in a Nigerian city: Implications for the success of the ongoing roll back malaria programme. Journal of Microbiology and Antimicrobials 3(9), 57-63.

Kinung'hi S.M., Mashauri F., Mwanga J.R., Nnko S.E., Kaatano G.M., Malima R., Kishamawe C., Magesa S. and Mboera L.E. (2010) Knowledge, attitudes and practices about malaria among communities: comparing epidemic and non-epidemic prone communities of Muleba district, North-western Tanzania. BMC public health 10(1), 395.

Lu F., Culleton R., Zhang M., Ramaprasad A., von Seidlein L., Zhou H., Zhu G., Tang J., Liu Y. and Wang W. (2017) Emergence of indigenous artemisinin-resistant Plasmodium falciparum in Africa. New England Journal of Medicine 376(10), 991-993.

Makoge V., Ndzi E., Mbah G., Nkengazong L., Matsebo ${ }^{1}$ A. and Moyou ${ }^{1}$ R. (2013) Status of malaria-related knowledge in school-going children in Cameroon. Archives of Applied Science Research 5(1), 105-111.

Mazigo H.D., Obasy E., Mauka W., Manyiri P., Zinga M., Kweka E.J., Mnyone L.L. and Heukelbach J. (2010) Knowledge, attitudes, and practices about malaria and its control in rural northwest Tanzania. Malaria Research and Treatment 2010.
Moyou-Somo R., Essomba P., Songue E., Tchoubou N.N., Ntambo A., Hiol H.N., Kemajou J.P., Essi M.-J. and Millet P. (2013) A public private partnership to fight against malaria along the Chad-Cameroon pipeline corridor: I. Baseline data on socioanthropological aspects, knowledge, attitudes and practices of the population concerning malaria. BMC public health 13(1), 1023.

Ndo C., Menze-Djantio B. and Antonio-Nkondjio C. (2011) Awareness, attitudes and prevention of malaria in the cities of Douala and Yaoundé (Cameroon). Parasites \& vectors 4 (1), 181.

Nga E.N., Moukoko E.C.E., Ngene J.P., Ewoudou M.E.R. and Mpondo E.M. (2015) Évaluation Pharmacotechnique des Molécules Antipaludiques du Marché Légal et du Marché Illicite à Yaoundé: Cas de l'Arteméther-Luméfantrine 20/120. HEALTH SCIENCES AND DISEASES 16(2).

Nsagha D. S. N.N.M., Assob Nguedia J. C., Zofou D., A. L. Njunda, and B. A. Ekosso Djombe. ( 2013) Prévention du Paludisme Chez des Mères d'Enfants de 0-5 ans à Bépanda, Douala. . African Journal of Integrative Health 2(1), 4-9.

Nsagha D.S., Njunda A.L., Kamga H.L.F., Nsagha S.M., Assob J.N., Wiysonge C.S., Tabah E.N. and Njamnshi A.K. (2011) Knowledge and practices relating to malaria in a semi-urban area of Cameroon: choices and sources of antimalarials, selftreatment and resistance. Pan African Medical Journal 9 (1).

Ocan M., Bwanga F., Bbosa G.S., Bagenda D., Waako P., Ogwal-Okeng J. and Obua C. (2014) Patterns and predictors of selfmedication in northern Uganda. PloS one 9 (3), e92323.

Ocan M., Obuku E.A., Bwanga F., Akena D., Richard S., Ogwal-Okeng J. and Obua C. (2015) Household antimicrobial self-medication: a systematic review and meta-analysis of the burden, risk factors and outcomes in devel- 
oping countries. BMC public bealth 15(1), 742.

Omole M. and Onademuren O. (2010) A survey of antimalarial drug use practices among urban dwellers in Abeokuta, Nigeria. African Journal of Biomedical Research 13(1), 1-7.

Paloque L., Ramadani A.P., Mercereau-Puijalon O., Augereau J.-M. and Benoit-Vical F. (2016) Plasmodium falciparum: multifaceted resistance to artemisinins. Malaria journal 15(1), 149.

Paula Martins A., da Costa Miranda A., Mendes Z., Soares M.A., Ferreira P. and Nogueira A. (2002) Self-medication in a Portuguese urban population: a prevalence study. Pharmacoepidemiology and drug safety 11(5), 409-414.

Sapkota A.R., Coker M.E., Goldstein R.E.R., Atkinson N.L., Sweet S.J., Sopeju P.O., Ojo M.T., Otivhia E., Ayepola O.O. and Olajuyigbe O.O. (2010) Self-medication with antibiotics for the treatment of menstrual symptoms in southwest Nigeria: a cross-sectional study. BMC public health 10(1), 610.

Shah M., Omosun Y., Lal A., Odero C., Gatei W., Otieno K., Gimnig J.E., Ter Kuile F., Hawley W.A. and Nahlen B. (2015) Assessment of molecular markers for anti-malarial drug resistance after the introduction and scaleup of malaria control interventions in western Kenya. Malaria journal 14(1), 75.
Self-medication among Cameroonian mothers Kojom et al.,

White L.J., Flegg J.A., Phyo A.P., Wiladpai-Ngern J.H., Bethell D., Plowe C., Anderson T., Nkhoma S., Nair S. and Tripura R. (2015) Defining the in vivo phenotype of artemisinin-resistant falciparum malaria: a modelling approach. PLoS Medicine 12(4), e1001823.

White N.J. (2004) Antimalarial drug resistance. The Journal of clinical investigation 113(8), 10841092.

WHO (2000) Guidelines for the regulatory assessment of medicinal products for use in selfmedication. Geneva: WHO/EDM/ QSM00.1 World Health Organization.

WHO (2001) Drug resistance in malaria. Geneva: WHO/CDS/CSR/DRS/2001.4 World Health Organization.

WHO (2005) The Roll Back Malaria strategy for improving access to treatment through home management of malaria :54. www.who.int, Consulted on October 21, 2017.

WHO (2016) World malaria report. The World health organization, Geneva, Switzerland: 186 p. Available at www.who.int.

WHO (2017) "World Weather Information ServiceDouala". Retrieved October 2, 2017.

Wongsrichanalai C. and Sibley C. (2013) Fighting drug-resistant Plasmodium falciparum: the challenge of artemisinin resistance. Clinical Microbiology and Infection 19(10), 908-916.
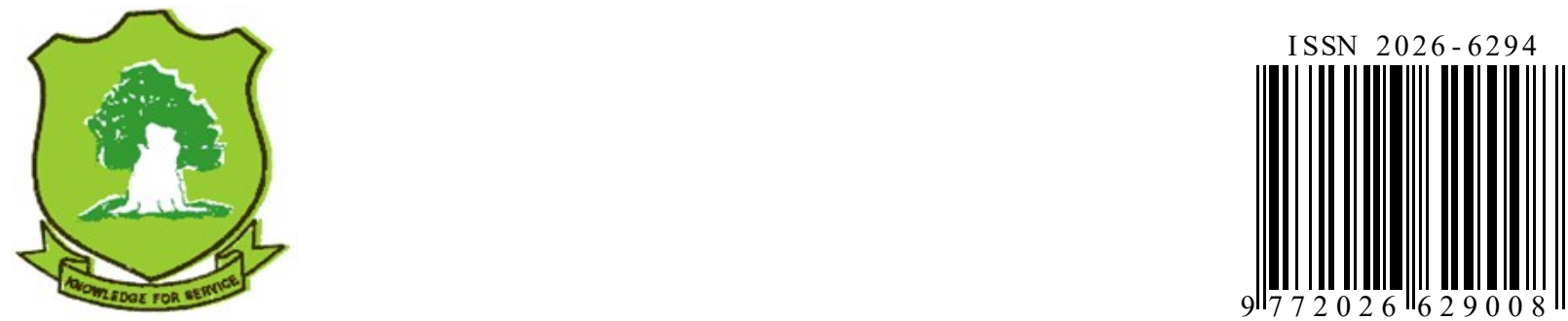